\title{
REFLETINDO SOBRE O APRENDIZADO DO PAPEL DE EDUCADOR NO PROCESSO DE FORMAÇÃO DO ENFERMEIRO ${ }^{1}$
}

Carla Natalina da Silva Fernandes ${ }^{2}$

Fernandes CNS. Refletindo sobre o aprendizado do papel de educador no processo de formação do enfermeiro. Rev Latinoam Enfermagem 2004 julho-agosto; 12(4):691-3.

Reflexão à luz das Novas Diretrizes Curriculares do Curso de Graduação em Enfermagem, cujo objetivo é destacar as características apontadas no documento sobre o papel de educador na formação do enfermeiro, discutindo ainda as implicações da relação professor-aluno nesse processo.

DESCRITORES: enfermagem; educação; capacitação

\section{REFLECTIONS ON LEARNING THE EDUCATIONAL ROLE IN THE NURSING FORMATION PROCESS}

Reflection in view of the new curricular lines for the undergraduate nursing course, aimed at highlighting the characteristics pointed out in the document on the role of educator in nursing formation and discussing the implications of the teacher-student relation in this process.

DESCRIPTORS: nursing; education; training

\section{REFLEXIÓN SOBRE EL APRENDIZADO DEL PAPEL DE EDUCADOR EN EL PROCESO DE FORMACIÓN DEL ENFERMERO}

Reflexión a la luz de las Nuevas Directrices Curriculares del Curso de Pregrado en Enfermería, con objeto de destacar las características apuntadas en el documento sobre el papel del educador en la formación del enfermero, discutiendo aún las implicaciones de la relación profesor-pupilo en este proceso.

DESCRIPTORES: enfermería; educación; capacitación

\footnotetext{
${ }^{1}$ Pesquisa vinculada ao Núcleo de Estudos e Pesquisas em Saúde Integral (NEPSI), financiada pelo CNPq; ${ }^{2}$ Acadêmica de Enfermagem, Bolsista de Iniciação Científica-CNPq, e-mail: carlanatalina@bol.com.br
} 
INTRODUÇÃO

A passagem pelas várias disciplinas e experiências oriundas do processo ensino-aprendizagem em Enfermagem, do qual somos sujeitos como aprendizes e educadores, nos faz questionar vários aspectos da educação, vivenciados nos estágios, na coordenação de grupos com pacientes e na coordenação de aulas na Universidade. Como motivar o outro para aprender? Em que nível devemos manter a relação com aquele que compartilha o que ensinamos, mais ou menos formal? Existe um modelo a seguir?

No desenvolvimento da aprendizagem, a posição que o professor assume na relação com o aluno deve ser alicerçada no respeito ao indivíduo, na confiança, na percepção do aluno como um ser integral, para que esse possa se perceber melhor como pessoa, passando então a perceber melhor os outros e, conseqüentemente, exercer melhor seu papel como pessoa e profissional ${ }^{(1)}$. Isso favorece mudanças na forma de sentir, pensar e atuar do aprendiz, por considerar o ser humano na sua totalidade ${ }^{(2)}$.

O objetivo deste trabalho é propiciar a reflexão à luz das Novas Diretrizes Curriculares do Curso de Graduação em Enfermagem ${ }^{(3)}$, a respeito das características apontadas no documento sobre a formação do enfermeiro no papel de educador, através de reflexão teórica, balizada pelo documento do MEC e a literatura especializada sobre o tema.

\section{O PAPEL DA EDUCAÇÃO E DO EDUCADOR NA FORMAÇÃO DO ENFERMEIRO}

A educação se constitui na mola mestra para a transformação dos paradigmas da existência humana, sendo um instrumento que possibilita ao homem compreender o que ocorre na sociedade, ampliando sua visão sobre o mundo em que está inserido.

As Novas Diretrizes Curriculares para a Graduação em Enfermagem sinalizam a necessidade de mudança paradigmática na educação em Enfermagem, cujos objetivos, entre outros aspectos, é de "levar os alunos dos cursos de graduação em saúde a aprender a aprender que engloba aprender a ser, aprender a fazer, aprender a viver juntos e aprender a conhecer..."(3).

A educação "bancária" que privilegia a simples transmissão do saber (depósito), viabilizada através dos currículos recheados de disciplinas que fragmentam o processo de ensino/aprendizagem, é, nesse momento, colocada em cheque, abrindo possibilidades para o estabelecimento de novos modelos acadêmicos com ênfase no papel do aluno como sujeito ativo do seu aprendizado e na valorização dos professores ${ }^{(4)}$.

A transformação no contexto da Educação em Enfermagem se dará no instante em que os atores da relação professor/aluno perceberem a importância de seus papéis no processo de ensinar, sendo mais conscientes, responsáveis em aprender, valorizando a comunicação, que possibilita a articulação das ações e a integração dos envolvidos, movidos pelo agir comunicativo, o que gera condições de um membro interagir com o todo ${ }^{(5)}$.

Alguns estudos ${ }^{(1,6-8)}$ mostram que, a partir do autoconhecimento e auto-reflexão, o aluno pode tornar-se mais consciente de suas responsabilidades e de seus atos, o que certamente, facilita o processo de aprendizagem.

\section{EDUCADORES E AS RELAÇÕES HUMANAS NAS NOVAS DIRETRIZES CURRICULARES DO CURSO DE GRADUAÇÃO EM ENFERMAGEM}

No documento aprovado pelo MEC, identificamos nas Diretrizes Curriculares de Graduação em Enfermagem aspectos que privilegiam a formação do enfermeiroeducador bem como a influência da relação professoraluno, nesse processo. As Competências e Habilidades ${ }^{(3)}$, específicas para essa ação, indicam que o enfermeiro egresso deve ser capaz de:

"Planejar, implementar e participar dos programas de formação e qualificação contínua dos trabalhadores de enfermagem e de saúde; planejar e implementar programas de educação e promoção à saúde, considerando a especificidade dos diferentes grupos sociais e dos distintos processos de vida, saúde, trabalho e adoecimento"(3).

Durante a formação, o aluno de Enfermagem deverá desenvolver essas competências e habilidades para atuar como educador. Esse aprendizado pode ser vivenciado, por exemplo, em cada espaço da prática, na abordagem de pacientes e sua família, individualmente ou em grupos, nos estágios de administração e ainda nos programas de capacitação de profissionais da equipe de 
Enfermagem.

Quanto aos Conteúdos Curriculares, apresentados pelas diretrizes que contemplam o Ensino de Enfermagem, é clara a indicação de "conteúdos pertinentes à capacitação pedagógica do enfermeiro, independente da Licenciatura em Enfermagem"(3). Em nossa experiência, o desenvolvimento desse aspecto, ao longo do Curso, facilita o aprendizado da postura de educador, já que somos chamados a desenvolver ações educativas na comunidade e nos mais variados e/ou adversos campos de atuação profissional.

No que diz respeito à Organização do Curso ${ }^{(3)}$, relativo à sua estruturação, o curso deverá assegurar ao acadêmico: "A visão de educar para a cidadania e a participação plena na sociedade; A definição de estratégias pedagógicas que articulem o saber, o saber fazer e o saber conviver, visando desenvolver o aprender a aprender, o aprender a ser, o aprender a fazer, o aprender a viver juntos e o aprender a conhecer que constitui atributos indispensáveis à formação do enfermeiro; A valorização das dimensões éticas e humanísticas, desenvolvendo no aluno e no enfermeiro atitudes e valores orientados para a cidadania e para a solidariedade; $A$ articulação da graduação em enfermagem com a licenciatura em enfermagem"(3).

Percebemos, dessa forma, que há enorme desafio e, ao mesmo tempo, estímulo para a formação do enfermeiro como educador. Por outro lado, notamos a grande responsabilidade das instituições formadoras para colocar em ação as indicações das Diretrizes Curriculares, tendo em vista que isso depende da ação humana, concretizada, entre outros caminhos, através da relação professor-aluno.

\section{REFERÊNCIAS BIBLIOGRÁFICAS}

1. Esperidião E. Holismo só na teoria: a trama dos sentimentos do acadêmico de enfermagem sobre sua formação. [Dissertação] Ribeirão Preto (SP): Escola de Enfermagem de Ribeirão Preto-SP/ USP; 2001.

2. Morin E. Os sete saberes necessários à educação do futuro. São Paulo (SP): Cortez; 2002.

3. Ministério da Educação e Cultura (BR). Diretrizes Curriculares Nacionais do Curso de Graduação em Enfermagem. Brasília (DF): Ministério da Educação e Cultura; 2001.

4. Noronha AB, Sophia D, Machado K. Formação Profissional em Saúde. RADIS comunicação FIOCRUZ outubro 2002; (3):11-7.

\section{CONCLUSÃO}

Os dilemas que experimentamos no aprendizado do papel de educador, durante a graduação em Enfermagem, nos motivaram a indagar sobre a relação professor-aluno e seus reflexos no processo de formação do enfermeiro. Entendemos que a educação constitui-se no pilar da transformação dos paradigmas sociais e humanos, podendo promover mudanças na forma de sentir, pensar e atuar das pessoas em relação a si mesmas e aos outros.

Nas Novas Diretrizes Curriculares do Curso de Graduação em Enfermagem, identificamos vários pontos que abordam a formação do enfermeiro como ser holístico que desempenha o papel de educador em todas as suas atuações. Por sua vez, é através de uma postura humana e competente que o professor pode ter atuação transformadora na formação de novos profissionais.

Isso tudo nos leva a acreditar que há grande influência da relação que o professor estabelece com o aluno, para que se cumpram as Novas Diretrizes Curriculares do Curso de Graduação em Enfermagem para a formação de cidadãos conscientes de seu papel social. Acreditamos que o processo de aprendizagem possibilita ao indivíduo sair da rotina do conhecido e procurar novas formas de interpretações da realidade, e é exatamente através dessa perspectiva que acreditamos ser viável ao profissional enfermeiro ser capaz de transformar a realidade da saúde através da sua ação educativa. "O aluno só aprende a aprender quando cria. É preciso que seu pensamento deixe de ser instrumento de passividade, conformismo e submissão para tornar-se um ato libertador, ${ }^{\prime(8)}$.

5. Peduzzi M. Equipe multiprofissional de saúde: conceito e tipologia. Rev Saúde Pública 2001; 35(1):103-9.

6. Saeki T, Munari DB, Alencastre MB, Souza MCBM. Reflexões sobre o ensino da dinâmica de grupo para alunos de graduação em enfermagem. Rev Esc Enfermagem USP 1999 dezembro; 33(4):342-7.

7. Esperidião E, Munari DB, Stacciarini JMR. Desenvolvendo pessoas: estratégias didáticas facilitadoras para 0 autoconhecimento na formação do enfermeiro. Rev Latinoam Enfermagem 2002 julho-agosto; 10(4):516-22.

8. Maldonado MT, Canella P. Recursos de relacionamento para profissionais de saúde: a boa comunicação com clientes e seus familiares em consultórios, ambulatórios e hospitais. Rio de Janeiro (RJ): Reichann \& Affonso Editores; 2003. 